\title{
East Mediterranean Experiences in TEVAR
}

\author{
Alptekin Yasim 1 , Erdinç Eroğlu'
}

1) Kahramanmaraş Sütçü İmam University, Faculty of Medicine, MD. Kahramanmaraş / Turkey

\section{Dear Editor,}

While there are numerous diseases of the thoracic aorta, the two most commonly encountered clinical conditions are dissection and aneurysms. Classic surgical treatment of these conditions is difficult for patients because of its high mortality and morbidity rates, as well as being tiring and laborious for the surgeon. Endovascular methods are therefore becoming increasingly popular in the treatment of these diseases.

It was reported that rates of 30-day and in-hospital mortality, stroke, permanent dialysis, and permanent paraparesis and paraplegia were $4.7 \%, 2.1 \%, 0.5 \%$, and $0.5 \%$ respectively for thoracic aortic aneurysms. ${ }^{(1)}$ Otherwise thoracic endovascular aneurysm repair (TEVAR) had similar immediate and delayed motor deficits and early mortality but lower dialysis, respiratory failure, and intensive care unit stay compared to open surgical repair. Early mortality after TEVAR was lower in septuagenarians, glomerular filtration rate of less than $60 \mathrm{~mL} / \mathrm{min}$, chronic obstructive pulmonary disease, defined as target population that had fourfold mortality reduction attributable to TEVAR. ${ }^{(2)}$

One study comparing open surgery and endovascular therapy in thoracic aorta dissections reported mortality rates of $26.6 \%$ and $13.1 \%$, respectively, in thoracoabdominal dissection and of $16.9 \%$ and $9.5 \%$, respectively, in thoracic dissection. ${ }^{(3)}$ That study also reported significantly higher morbidity rates, including cardiac, respiratory, and genitourinary complications, hemorrhage, and acute renal failure, in patients undergoing open repair.

We also attach particular importance to endovascular interventions in thoracic aorta pathologies in our clinic. Endovascular interventions were performed on 18 patients at the Kahramanmaraş Sütçü İmam University Faculty of Medicine, Cardiovascular Surgery Depart- 
ment in 2012-2018. Aneurysm was present in seven of these (six thoracoabdominal and one thoracic), dissection in nine, and aortic tear in two. TEVAR was applied to patients with dissection, aortic tear, and thoracic aorta aneurysm, while patients with thoracoabdominal aortic aneurysm received multilayer stent implantation.

Seventeen patients were men, with one woman. Mean age of the patients with aneurysm was 71.1 (5282) year, and was 59.4 (32-83) year in the patients with dissection and 27.5 (19-48) year in those with aortic tear. The most common risk factor was hypertension, followed by smoking. Sixteen patients were operated under elective conditions, and two under

Figure 1 - a

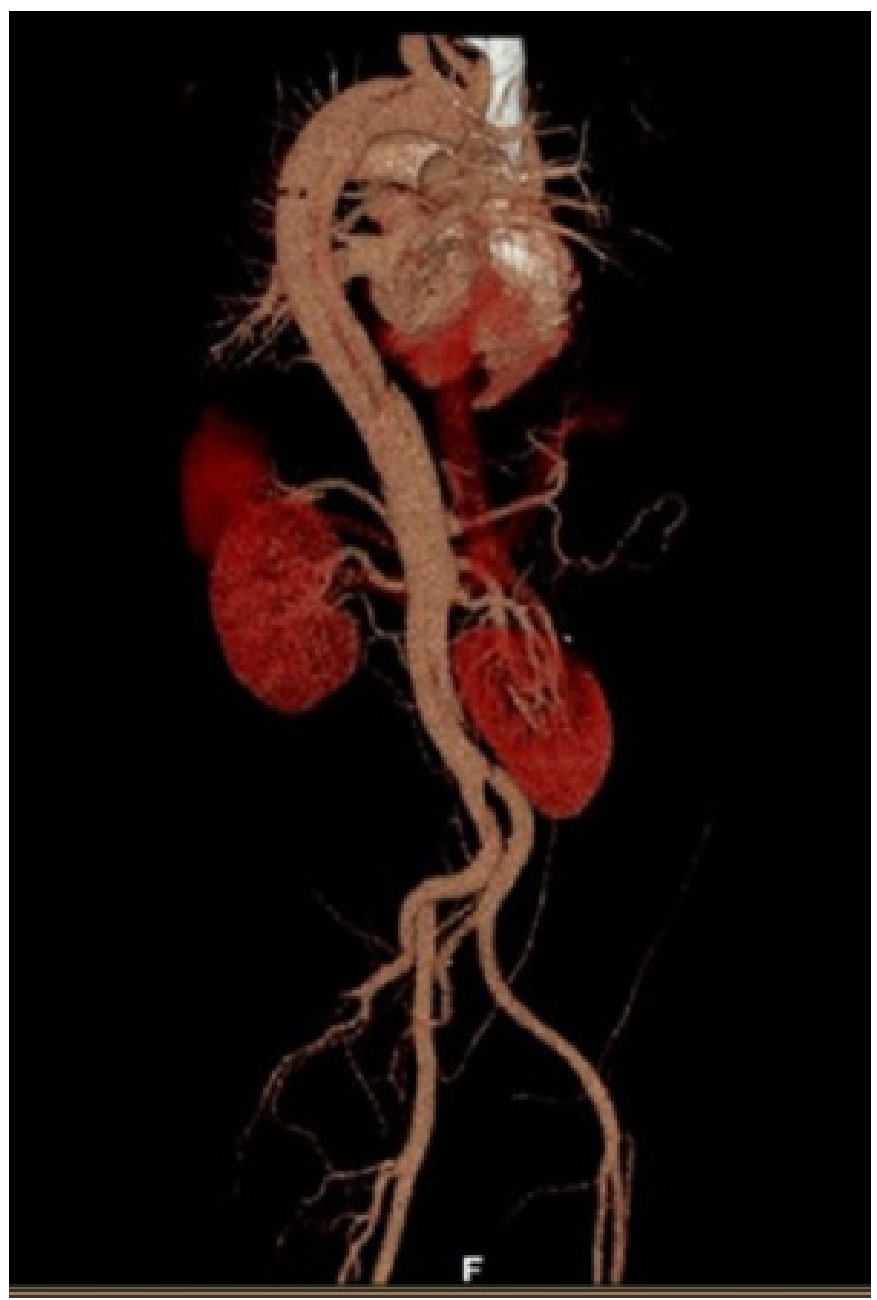

emergency conditions. One 82-year-old patient undergoing emergency procedures due to dissection died on the second day postoperatively. Figure $1 \mathrm{a}$ and $\mathrm{b}$ show pre- and post-procedural computed tomography angiography images in a patient receiving TEVAR due to dissection, and Figure $2 \mathrm{a}$ and $\mathrm{b}$ in a patient undergoing multilayer graft implantation. The other 17 patients were followed-up for a mean 5-68 months (mean: 28.4 months). All patients were living and in good condition.

In conclusion, with their low mortality and morbidity rates, endovascular interventions are good alternative to open surgery in thoracic aorta pathologies.

Figure 1 - b

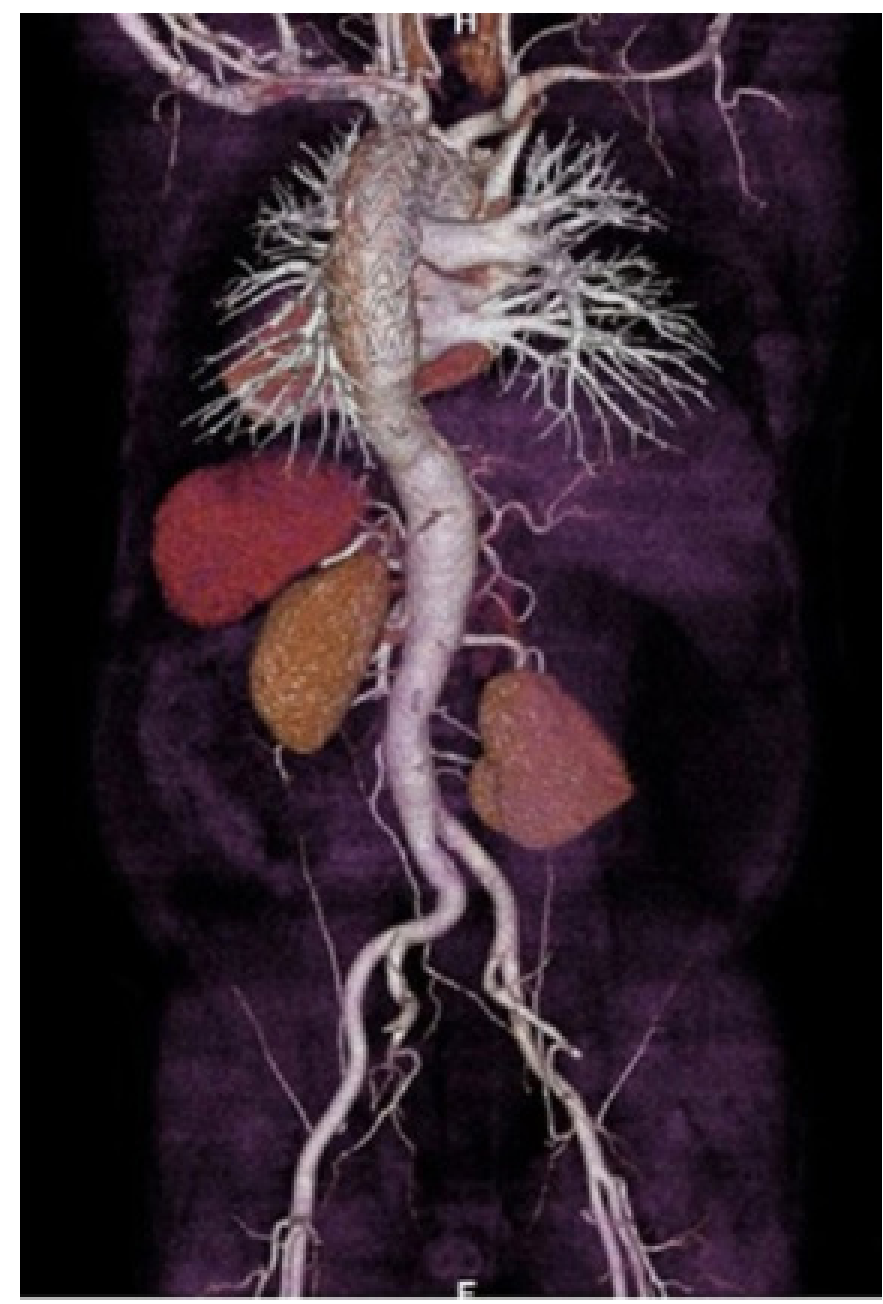

Yasim A., Eroğlu E. East Mediterranean Experiences in TEVAR. EJCM 2018; 06 (3): 80-82. Doi: 10.15511/ejcm.18.00232. 
Figure 2 - a

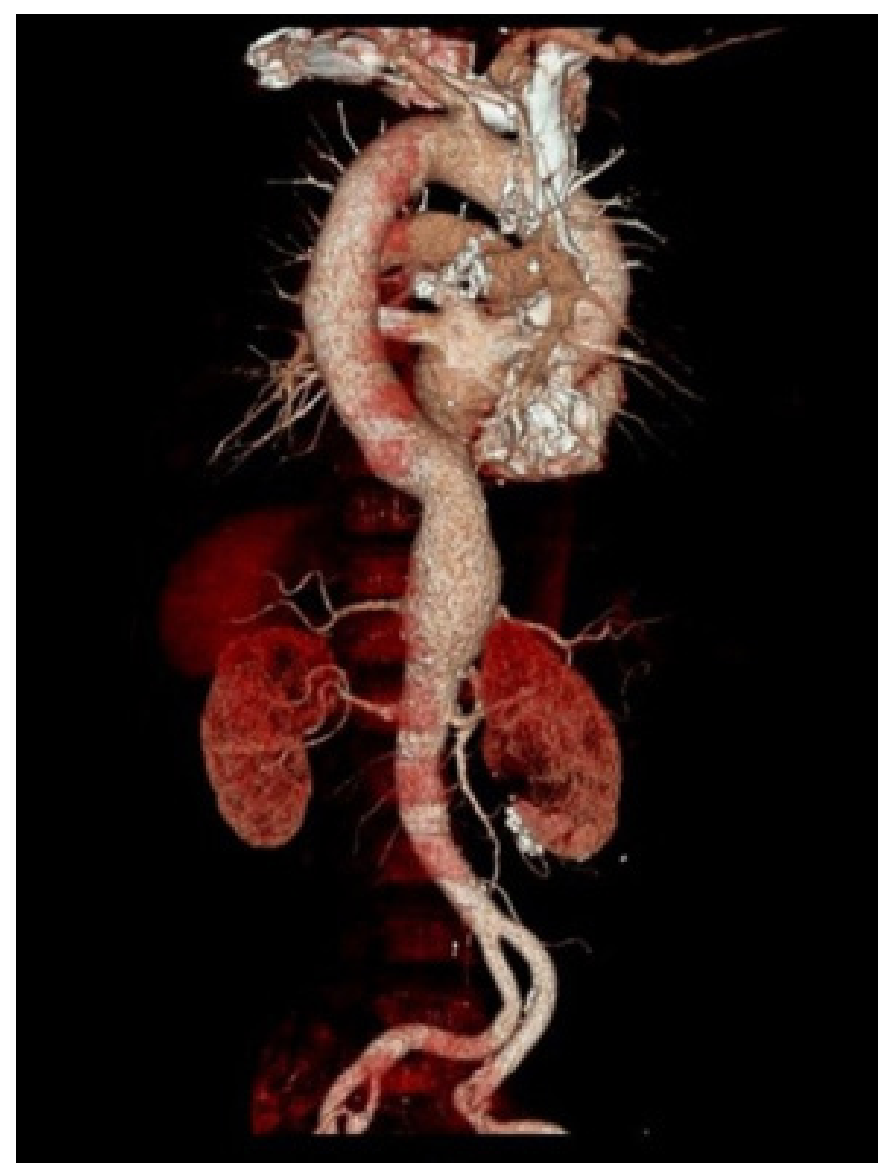

\section{References}

1. Ranney DN, Cox ML, Yerokun BA, Benrashid E, McCann RL, Hughes GC. Long-term results of endovascular repair for descending thoracic aortic aneurysms. J Vasc Surg. 2018 Feb;67(2):363-368.

2. Tanaka A, Sandhu HK, Pratt WB, Afifi R, Miller CC 3rd, CharltonOuw K, Codreanu ME, Saqib NU, Azizzadeh A, Safi HJ, Estrera AL. Risk Modeling to Optimize Patient Selection for Management of the Descending Thoracic Aortic Aneurysm. Ann Thorac Surg. 2018 Mar;105(3):724-730.

3. Sachs T. Pomposelli F, Hagberg R, Hamdan A, Wyers M, Giles K, Schermerhorn M.Open and endovascular repair of type B aortic dissection in the Nationwide Inpatient Sample. J Vasc Surg. 2010 Oct;52(4):860-6.
Figure 2 - b

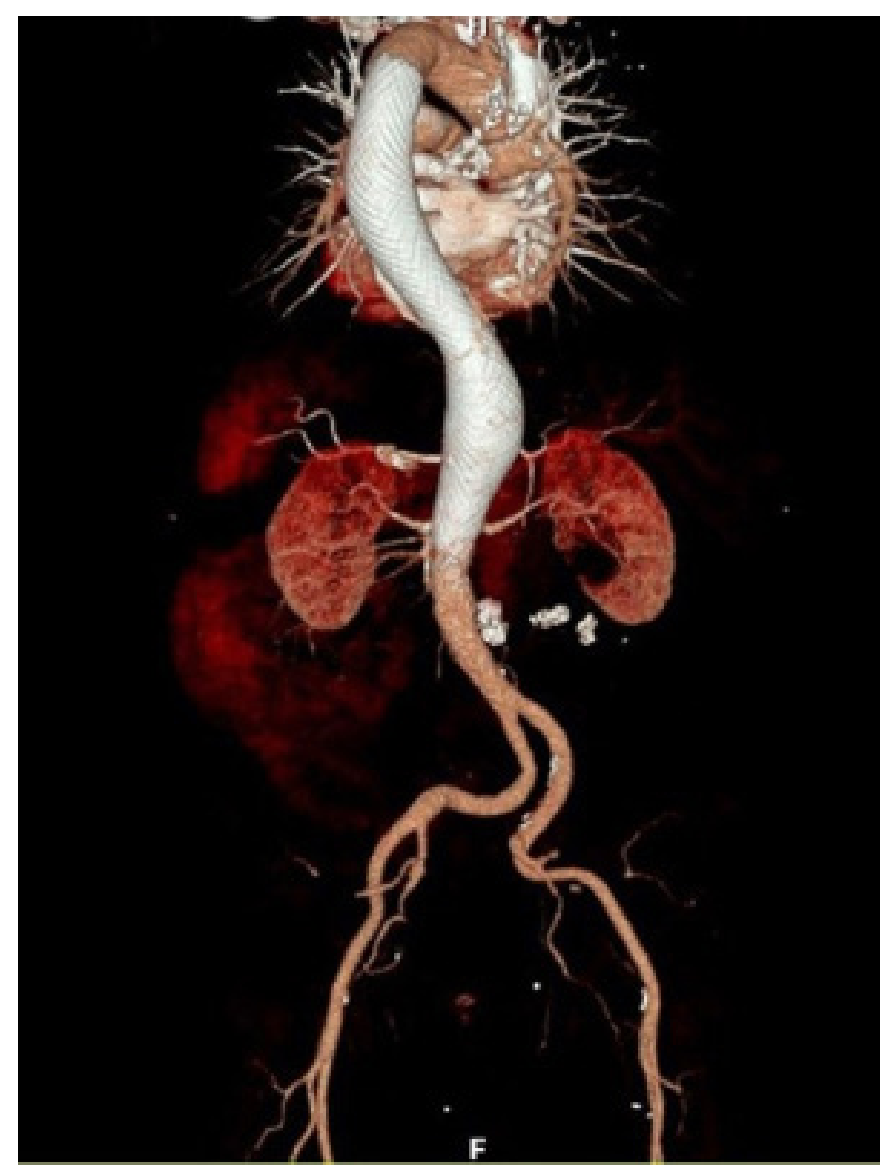

Received: 24/05/2018

Accepted: 18/08/2018

Published: 15/09/2018

Disclosure and conflicts of interest:

The authors declare no conflict of interest.

\section{Corresponding author:}

Alptekin Yasim

Mail: alpyasim@hotmail.com 